\title{
Epistemic Angst, Intellectual Courage and Radical Scepticism
}

\author{
Genia Schönbaumsfeld
}

(forthcoming in International Journal for the Study of Skepticism)

\section{Introduction}

In this paper I examine the question of what motivates radical sceptical scenarios and how one might resist both the philosophical and the psychological moves that appear to make it compulsory. To this end, I distinguish between three different ways of motivating scepticism that are prevalent in the contemporary literature, but that are usually not distinguished: recent envatment, lifelong envatment, and 'nothing but envatment'. Recent envatment scenarios (RE) are a kind of 'local' sceptical scenario, whereas lifelong envatment (LE) and 'nothing but envatment' (NBE) are global or radical sceptical scenarios that attack the very idea that anyone has ever had perceptual contact with an 'external' thing (what Stroud (1984) calls 'external world scepticism')'.

The strategy pursued is as follows. In the next section I consider local sceptical scenarios, in order to show that such scenarios by themselves are not sufficient to motivate the 'global' variety. Then, in section III, I show that it is the implicit acceptance of the Reasons Identity Thesis (RIT) - the thought that whether I am in the good case or in the bad case, my perceptual reasons are the same - which leads to a receding of the world behind a

\footnotetext{
${ }^{1}$ LE is less radical than NBE, where we are supposing there is no 'external world' at all. LE leaves intact the notion that there is an 'external world' in which my envatted brain exists, but I have never had any access to this world. These scenarios are often not distinguished, but I think that we should distinguish them. LE is a radicalized version of RE, but NBE is, in a sense, merely a contemporary version of the Cartesian sceptical scenario where there is nothing but my mind and its impressions, and there is no way of determining where these impressions come from (if, indeed, they come from anywhere).
} 
'veil of perception', and forces radical sceptical scenarios (LE and NBE) upon one. Since this thesis can be resisted, so can global scepticism.

The overarching aim of the paper is to persuade the reader that radical scepticism is driven less by independently plausible arguments and more by a fear of epistemic limitation which can be overcome. By developing, in the final section, the Kierkegaardian insight that knowledge requires courage, I show that we are not, as potential knowers, just passive recipients of a passing show of putatively veridical information, we also actively need to put ourselves in the way of it by learning to resist the temptation to think that knowledge is forever out of reach because a 'view from nowhere' is impossible.

\section{Recent Envatment Scenarios and Arguments from Perceptual Illusion}

Let's start by asking, what are recent envatment scenarios? Well, similarly, to other local sceptical scenarios, such as Dretske's famous zebra example (Dretske 1969), a recent envatment scenario casts doubt on particular, 'local' perceptual knowledge claims, rather than attacking the very idea that perceptual knowledge is ever possible. Thus, local sceptical scenarios give one grounds for doubt about particular perceptual cases (or larger swathes of them), while leaving intact the thought that perceptual knowledge is sometimes available ${ }^{2}$. Applied to brain-in-a-vat (BIV) scenarios this implies arguing for recent envatment, rather than lifelong envatment or 'nothing but envatment', as both of the latter scenarios attack the notion that perceptual knowledge is ever possible. In LE I have always been a BIV and have therefore never been in touch with an 'external world', but only with electrode stimulations,

\footnotetext{
${ }^{2}$ I am here concerned only with making the point that while local sceptical scenarios can give one reason to doubt the veridicality of one's current perceptual experience, they do not motivate the thought that perception as such gives one no access to the 'external world' and can thus never be veridical (even in principle).
} 
whereas in 'nothing but envatment' there may be nothing else at all except me and my vat. This is a kind of metaphorical BIV scenario analogous to Descartes' evil demon argument, where we are discounting the notion that someone must have set up the vat and is continuing to service $\mathrm{it}^{3}$.

$\mathrm{RE}$, on the other hand, involves taking the BIV scenario au pied de la lettre. It presupposes the following: that there is a world, for example, in which the vat containing my brain exists; that there are evil scientists (or robots or aliens or what-have-you) who have caused me to become envatted (or who have 'bred' 'me' - my brain - to be envatted); that it is scientifically possible to separate brains from bodies without killing off the brain; that I might find out about my previous envatted state by, for instance, having my brain 'reinserted' into my body etc. This, as it were, literal fleshing-out of the sceptical scenario is precisely what turns it into a 'local' case: if I imagine that I might be the victim of such a predicament, this does not imply that anyone else is, or, indeed, that the 'external world' as such does not exist (since, as we have just seen, a world containing vats, brains and evil scientists is in fact presupposed by this form of scepticism). All it implies is that, for as long as I am a BIV, many of my current perceptual beliefs about the world are false.

It is important to note here, however, that not all of my beliefs about the world will be false. Since I have formerly interacted with the world in the normal way, many beliefs I hold about the state of this world will survive envatment. For example, it remains true that London is the capital of England, that Great Britain is a small island off the Continent, that cats are mammals etc. Consequently, many of my beliefs about these things will remain true postenvatment also. RE will therefore mainly pose a threat to my current perceptual beliefs - e.g. about there being a computer in front of me, or a tree, or a person etc. It is important to

\footnotetext{
${ }^{3}$ If one prefers to think of Descartes' evil demon scenario as one where an actual demon is causing my perceptions, on the other hand, this would make it more similar to an LE scenario (where NBE is more radical even than that).
} 
emphasize this, as this fact poses a major stumbling block to any attempt at generalizing local sceptical arguments to get one the 'global' conclusion that if one can sometimes - or very often - be wrong, it is possible that one could always be wrong (i.e. be wrong in every case ${ }^{4}$ ), and, hence, that one cannot be certain that one has access to reality (an 'external world" ${ }^{5}$ ) at all $^{6}$.

If this is right, then RE scenarios cannot accomplish much more than arguments from perceptual illusion, which are similarly unable to get one from local to global error. That is to say, just as RE does not imply LE or NBE, so the possibility of perceptual error or illusion does not imply systematic or 'global' perceptual unreliability. For example, I am only able to determine that when I look at a square tower from a distance, it will appear round, because I can trust my perception that from close-by it looks square, and there is a scientific explanation available that can tell me why it nevertheless appears round from some way off. If perception in general were deceptive, I could not make the judgment that perceptual appearances are sometimes misleading. All I could do would be to report, for instance, that at time $\mathrm{t} 1 \mathrm{I}$ have the impression that 'thing 1 ' that I see is square, while at time $\mathrm{t} 2 \mathrm{I}$ have the impression that 'thing 2' that I see is round. And since 'thing 1' and 'thing 2' might, for all I know, be different things, I could not even conclude that one perceptual experience might be an accurate representation of the way things are, while the other might not. But if I cannot make this judgement, I am similarly unable to conclude that at time $\mathrm{t} 2 \mathrm{I}$ am being misled, for my perceptual experience at $\mathrm{t} 2$ would only be misleading if it were an experience of the same thing that $\mathrm{I}$ encountered at $\mathrm{t} 1$, so that my reports at $\mathrm{t} 1$ and $\mathrm{t} 2$ would turn out to be in conflict with each other. As long as I have no reason for assuming that my perceptual experiences of

\footnotetext{
${ }^{4}$ It is in any case a fallacy to think that because one could be wrong in any one case, it is possible to be wrong in every case.

${ }^{5}$ I have put quotation marks around 'external world', as I am challenging the Cartesian idea that we could be locked into an 'internal' world of appearances, from the perspective of which the existence of an 'external' world could be doubtful.

${ }^{6}$ For more on this, see The Illusion of Doubt, chapter 2.
} 
'thing 1' and 'thing 2' are in fact experiences of the same physical object, however - which, of course, I would not if perception were generally defective (for then I would have no grounds for trusting one report more than the other; I would rather have to assume they are equally misleading) - there is no way of determining that a perceptual 'illusion' has in fact occurred. All I could say is that I am having different perceptions at different times, but this, of course, does not suffice to allow me to infer that at time t2 I was misled, and, hence, that perceptual errors are possible.

In other words, just as we need to presuppose the existence of an 'external world' that is broadly like our own in order to get the RE scenario off the ground, so perception must generally be taken to be reliable if an 'argument from illusion' is to be constructed. So, what makes local sceptical scenarios possible is the very thing that they are, ironically, drafted in to undermine: a background of generally veridical perceptual experience. In this respect, RE is just a souped-up, 'sci-fi' version of the more pedestrian arguments from illusion and cannot, for this reason, achieve more than they can: to show that perceptual error is possible (that human beings are fallible). But an appeal to fallibility alone is not enough to get one the conclusion that everyone could be wrong about everything all of the time.

\section{The Cartesian Picture, the Reasons Identity Thesis and Global Scepticism}

So, what is it, then, that makes us worry about radical sceptical scenarios, such as LE and NBE, if local sceptical concerns give us no real reason to do so? For, clearly, most people don't entertain such global sceptical scenarios because they strike one as probable or in any 
way as evidentially motivated (in fact, quite the reverse) ${ }^{7}$. Rather, such scenarios seem compelling because they articulate a deep-seated anxiety human beings appear to have about their whole relation to the world: how do we know that we are ever in touch with something genuinely objective and 'external', and are not just locked into the cage of our own perspective? Both Thomas Nagel and Barry Stroud give potent expression to the fear that the very idea of possessing a point of view on the world, which is inherently limited by our particular perceptual and intellectual constitution, condemns us to the possibility that nothing in this world might be as we imagine it to be. Here, for example, is Nagel: 'Objectivity and scepticism are closely related: both develop from the idea that there is a real world in which we are contained, and that appearances result from our interaction with the rest of it' (Nagel (1986: 68)). Why does the fact that there is a real world open the door to radical scepticism? It is because, Nagel thinks, 'it seems to follow that the most objective view we can achieve will have to rest on an unexamined subjective base, and that since we can never abandon our own point of view, but can only alter it, the idea that we are coming closer to the reality outside it with each successive step has no foundation' (ibid.). In other words, unless we somehow manage to discard our own point of view in favour of what Nagel calls 'a view from nowhere' (Nagel (1986: 67)), we can never really know about the world as it is 'outside' of our own minds; including if there is one. Stroud raises similar concerns:

We are confined at best to what Descartes calls 'ideas' of things around us, representations of things or states of affairs which, for all we can know, might or might not have something corresponding to them in reality. We are in a sense imprisoned within those representations, at least with respect to our knowledge. Any

\footnotetext{
${ }^{7}$ An exception is Bostrom (2003), but his argument that it is more likely than not that we are actually living in a simulation relies on some highly controversial assumptions that I do not have the space to discuss here.
} 
attempt to go beyond them to try and tell whether the world really is as they represent it to be can yield only more representations, more deliverances of sense experience which themselves are compatible with reality's being very different from the way we take it to be on the basis of our sensory experiences. There is a gap, then, between the most that we can ever find out on the basis of our sensory experience and the way things really are. In knowing the one we do not thereby know the other (Stroud (1984: 32)).

The thought that we are 'imprisoned' by or locked into our own minds or perceptual experiences is, first and foremost, an expression of (what Pritchard calls) epistemic angst ${ }^{8}$. Epistemic angst is the fear of epistemic limitation, which in the guise just sketched, takes the form of anxiety over the very idea of having a point of view, or of being a creature with a mind capable of taking up a perspective on a (putatively) objective world. The underlying idea seems to be not only that our point of view is limited in all sorts of contingently fallible ways and may therefore never convey the full picture of what is 'out there', it also expresses the full-blown angst that our 'perspective' might not so much as provide a view on anything that we might be trapped in a mental cage with no beyond at all. It is this angst that fuels the Cartesian picture of our epistemic situation which conceives of the 'external world' not as something that is, in principle, directly present to the senses, but rather as something that we can only know about by dint of making inferences from our mental states or apparent 'perceptual' experiences. And once such a picture is in place, it indeed becomes hard to see

\footnotetext{
${ }^{8}$ See, for example, Pritchard $(2014,2016)$.
} 
how we could so much as know about this world beyond the 'veil of appearances' (compare Stroud (1984)), including whether it exists ${ }^{9}$.

But what, one might ask, does this fear ultimately derive from given that we need not accept, pace Nagel, that the very idea of possessing a point of view is epistemologically dubious? For why shouldn't we think instead that without a point of view, and without our particular perceptual capacities, no world could so much as be available to us in the first place? Rather than constituting the holy grail that can save as from epistemic devastation, one might think that a view from nowhere is a 'view' from which nothing can be seen. Given that any description of the world - no matter how 'superior' to our own - will eo ipso be a description from a particular vantage-point (employing particular concepts; rendered in a particular system of signs), the demand for an 'absolute conception of reality' 10 is like the demand for an 'absolute' description: the impossible desire for something magically selftranscending. For even God's own, 'superior' view would constitute only one particular and determinate way of conceiving of the world. If it were otherwise, it could not be a view on a world at all - a view from nowhere is a contradiction in terms.

If this is right, however, then why think of the mind as a cage? Stroud (1984) appears to think that it is Descartes' dreaming argument that forces such a conception upon us - that if we cannot show in advance of relying on any particular perception that we are not dreaming, then we cannot trust any perception to constitute accurate input about the way things are (as there might be no way things are).

\footnotetext{
${ }^{9}$ Berkeley had this concern too, which is what prompted him to deny that there are 'external' objects at all. Idealists, in effect, close the appearance/reality 'gap' by claiming that all is appearance. But this strategy is selfundermining in a way similar to the dreaming argument (see below) - i.e. it requires being able to draw the distinction (between appearance and reality, or subject and object) that the conclusion of the argument then goes on to undermine.

${ }^{10}$ See Bernard Williams (1978) and my discussion of the absolute conception in the Conclusion to The Illusion of Doubt.
} 
Again, this move is not as compulsory as it might seem. For if we cannot trust any perception without already having shown in advance that it is not 'dream perception', how can we even know what 'dream perception' is or that it implies that what we have taken to be real while asleep in bed was just generated by our slumbering minds? Given that the distinction between being awake and being asleep is not an a priori distinction, perception must have had some hand in enabling us to draw it. That is to say, if we didn't trust our perceptions that we have, for example, woken up and found ourselves in bed (rather than believing, like a moment ago, that we were flying through the air, say), how could we even know (or so much as believe) that we have been dreaming rather than that we are just continuing to 'perceive' things in a strange way ${ }^{11}$ ? And if we couldn't draw the distinction between actual perception and dream perception because no actual perception could ever count as actual perception before a proof that it is not dream perception has been given, then we would not even be entitled to believe that things are sometimes being perceived in a 'strange', 'dream-like' manner either, as any 'perception' we have would then be conceived as constituting just another aspect of reality or be part of one big, extended 'dream' ${ }^{12}$. But, if so, and similarly to the local sceptical scenarios we have already considered in the previous section, we can then not use 'dream perception' to cast doubt on 'actual' or 'real perception', for we would then only have one continuous kind of 'perception', whether we want to call it reality or 'grand dream'. And without the distinction between 'dream perception' and 'real perception', we would of course have no reason to call it 'grand dream' in the first place. Hence, the demand that a proof of 'real perception' must be given before we can trust any perception, seems entirely self-undermining, as it relies on the possibility of drawing the very

\footnotetext{
${ }^{11}$ That is to say, we couldn't even imagine the distinction unless we grant that perception can, in principle, be reliable even if we can't, at a particular moment in time, necessarily tell which is which.

${ }^{12}$ Penelope Maddy calls this idea 'extraordinary dreaming' in her 2017.
} 
distinction the argument is, at the same time, used to call into question: the sceptic is sawing off the branch on which she is sitting ${ }^{13}$.

It is worth emphasizing here that the point I have just made has nothing to do with the question of whether one can subjectively distinguish, once the distinction (between 'real perception' and 'dream perception') is already in place, between dreaming experience and waking experience. For while being asleep, we do not usually know that we are. But this does not invalidate the crucial point that I was trying to make earlier, namely, that if I start by not trusting any perceptions (by not being able to take any of them at face value), I will not be able to formulate a distinction between waking experience and dreams at all, and thus will not be able to use the distinction to cast doubt on the veracity of the former. Consequently, the dreaming argument, like other local sceptical scenarios, does not give us reason to believe that all of our perceptual claims might be false and hence that we have never had experience of a genuinely 'external' thing.

If not, however, then why should we accept dream scepticism's concomitant demand that unless we can subjectively distinguish waking experience from dreaming experience merely by attending to our present experience, we can never know that what we perceive is indeed so? Perhaps NBE or Descartes' malicious demon argument can help here: if I cannot know that I am not locked into a 'global' vat-world merely by examining my present perceptual experience, then how can I know anything?

But why should I accept even that? What reason, apart from its bare logical possibility, do I have for supposing that a NBE scenario might obtain (and logical

\footnotetext{
${ }^{13}$ In other words, without a proper basis for drawing an appearance/reality distinction, there is no viable sceptical argument either. And being able to draw a distinction means being able to observe a difference in our perceptual experience (e.g. a difference between 'waking' experience and 'dreaming' experience). But being able to observe such a difference requires being able to take some of our perceptual experiences at face value (i.e. as accurate representations of the way things are) - for example, those about how 'waking' experience differs from 'dreaming' experience. Consequently, the dreaming argument cannot undermine the credentials of perceptual experience as such (i.e. as in principle veridical).
} 
possibilities alone are not genuine reasons that speak in favour of something)? Perhaps we are misled by a false analogy here, akin to Stroud's plane-spotting example. If we were planespotters in a war who had learnt to identify particular planes by attending to particular features of the plane and we subsequently came to know that these features underdetermined the planes' identity, as these features were also found in other planes, then we would have to retract previous claims to know about the planes' exact identities. Stroud seems to think that this plane-spotting example is analogous to dreaming or global envatment scenarios, but that is actually not the case.

Here are some crucial differences that undermine the analogy. While in the planespotting scenario, it is possible to come to know that our plane-spotting ability is undermined by the presence of other planes with the same salient features, this is not so in the LE or NBE scenarios. NBE is not distinguishable from reality even in principle, whereas the planes could be distinguishable by learning to detect other features that could identify them uniquely. No even in principle comparison between NBE and reality is ever possible, as this would require shedding our own point of view, while such a remarkable feat is not necessary in the planespotting example. Consequently, that plane-spotting can, in certain circumstances, be underdetermined gives no sustenance to NBE, which is a quite different scenario (for in NBE we are asked to imagine that all our perceptual claims are false (not just that some of them are), even though there is no empirical evidence (such as in the plane-spotting case) either for or against such 'radical underdetermination'. So, we have again been given no additional reason to think that all of our perceptual experiences as a class could be false.

Hence, we seem to have returned to square one - it appears that serious consideration of LE and NBE is fuelled less by convincing argument and more by epistemic angst (by a bare, objectless fear of epistemic limitation), which makes us believe that the Cartesian picture of our evidential situation - the thought that we are, as Stroud says, 'imprisoned' in 
our representations - is somehow compulsory. And once this picture is in place, we are also inclined to accept the thought that unless we can subjectively distinguish the good from the bad case merely by attending to our perceptual phenomenology alone, we cannot know any of our perceptual claims to be true. But this 'indistinguishability thesis' does not follow independently of already having accepted the Cartesian picture, which has the radical sceptical problem built into it from the very start. It is easy to see this if we consider the following argument:

\section{The Indistinguishability Argument for 'External World' Scepticism}

P1. In the bad case, the supporting reasons for one's perceptual beliefs can only consist of the way the world appears to one.

P2. The good and bad cases are phenomenologically indistinguishable.

C1. So, the supporting reasons for one's perceptual beliefs in the good case can be no better than in the bad case. (From (P2))

C2. So, the supporting reasons for one's perceptual beliefs can only consist of the way the world appears to one. (From (P1), (C1) $)^{14}$

C3. If the supporting reasons for one's perceptual beliefs can only consist of the way the world appears to one, one can never know more than how the world appears. (From (C2))

C4. If one can never know more than how the world appears, one can only know appearances. (From (C3))

\footnotetext{
${ }^{14}$ I have borrowed this part of the argument from Pritchard (2008: 294).
} 
C5. If one can only know appearances, the 'external world' lies 'behind' a 'veil of appearances'. (From (C4))

C6. If the 'external world' lies 'behind' a veil of appearances, knowledge of the 'external world' is necessarily 'indirect' - i.e. rests on an inference from these appearances to an 'external reality'. (From $(\mathrm{C} 5))^{15}$

C7. But such inferences will only be valid if one already knows independently (of relying on those appearances) that appearances are a good guide to the 'external world'. (From (C6))

C8. But one cannot know this, precisely because one only has access to appearances and their testimony is inconclusive. (From (C3), (C4), (C5), (C6), (C7))

C9. So, there is no non-circular way of demonstrating (from appearances) that the 'external world' exists and knowledge of it is possible. (From (C8))

C10. But such a demonstration is nevertheless necessary, as the hypothesis that there is an 'external world' could be false, for one might be in an LE or NBE scenario. (From (C9))

C11. So, scepticism. ${ }^{16}$

The notorious step in this argument is clearly the move from (P2) to (C1). If we grant this move, we grant - at the same time - that we cannot know that there is an 'external world'. What a strong epistemological conclusion from an innocuous-seeming claim about the subjective indistinguishability of the good and the bad case! This prompts the question: is the move compulsory?

\footnotetext{
${ }^{15}$ For a good discussion of the dubiousness of C6, see Sosa (1997).

${ }^{16}$ Notice how (C3)-(C11) reproduce the structure of Wright's I-II-III argument for scepticism (Wright (2002: 338-9)).
} 
John McDowell (1998a, 1998b, 2009) was the first contemporary philosopher to notice that an endorsement of what he calls the highest common factor conception of perceptual reasons is the prop that radical scepticism depends on - the thought that my epistemic standing in the good case depends on taking the highest common factor of the good and the bad case which can only be non-factive ${ }^{17}$. In The Illusion of Doubt I call this notion the Reasons Identity Thesis - the view that my epistemic grounds, in both the good and the bad cases, must be the same.

Why would anyone accept this thesis given that it leads to radical scepticism? It seems only because I cannot qualitatively distinguish a good-case-experience from a badcase-experience merely by attending to my current mental state. But unless I am already antecedently and independently convinced of the truth of the Cartesian picture which sees me as imprisoned within my own representations, subjective indistinguishability alone is not enough to make the Reasons Identity Thesis (RIT) compulsory. For if one resists the nonmandatory move to $\mathrm{C} 1$, one can hold, against RIT, that 'good case' perception is factive: in the good case (where the environment is epistemically friendly) seeing that $\mathrm{P}$ can provide factive epistemic support for the belief that $\mathrm{P}$, while in the corresponding bad case - where the environment is epistemically unfriendly and one only seems to see that $\mathrm{P}$ - one does not have factive epistemic support for one's belief. And this disjunction holds, whether or not one can phenomenologically distinguish between the two cases.

That Crispin Wright (2002, 2008, 2014), like Stroud, believes, by contrast, that one needs to demonstrate that one is not dreaming (or not a BIV) before one can perceptually know anything about one's surroundings already reflects his antecedent commitment to RIT (the HCF conception), since only this forces one to accept the thought that the epistemic

\footnotetext{
${ }^{17}$ These insights have also been forcefully developed by Duncan Pritchard $(2009,2012)$.
} 
grounds ${ }^{18}$ one has access to are the highest common factor of the good case and the bad case, which can only be non-factive.

On the disjunctive view ${ }^{19}$, however, perceptual reasons do not, in the good case, fall short of the environmental facts, and consequently a lack of 'experiential markers' that would allow one introspectively to distinguish the good from the bad case is irrelevant ${ }^{20}$. Consequently, LE and NBE will only pose a threat to one's knowledge of the world if one already agrees that one's perceptual reasons can only consist of what is common to both the good and the bad cases, and to assume that is just what is to be proved (i.e. it would be question-begging).

So, we have, so far, been given no good independent grounds to accept the thought that we could be globally wrong because locked into an internal mental cage that forever occludes the world from view. Where, then, does this leave our fear of epistemic imprisonment and what could we do to combat it? Perhaps the Danish thinker, Søren Kierkegaard, can help us find an answer to these questions.

\section{Epistemic Angst and Intellectual Courage}

In the previous section I argued that implicit acceptance of the Reasons Identity Thesis (RIT), which leads to a receding of the world behind a 'veil of perception', is driven less by independently plausible arguments and more by a fear of epistemic limitation. We are

\footnotetext{
${ }^{18}$ I am using 'grounds' and 'reasons' interchangeably.

${ }^{19}$ For an excellent defence of epistemological disjunctivism, see Pritchard (2012).

${ }^{20}$ Furthermore, it is unclear how 'experiential markers' could so much as help in the first place. For if there were a marker that 'said' to us 'I'm a veridical experience', how would we know how to trust it? The very idea either leads to an infinite regress (as we would need another experience or marker to confirm the veridicality of the first and so on ad infinitum), or we would have to appeal to a 'self-guaranteeing' marker - a marker that is, as it were, 'incorrigible', but it is hard to see how to make sense of such a notion.
} 
sometimes seduced by the thought - as Nagel clearly is - that there is something epistemologically suspect about our very subjectivity. But if I am right that we are not rationally required to accept this conclusion, we need to find a way to resist this temptation. That is to say, we must find the intellectual courage to overcome the anxiety that the very possession of a point of view constitutes an epistemic shortcoming. We can only do this, however, if we first expose some of the underlying (and perhaps subconscious) motivations that nourish this angst, and this is where Kierkegaard comes in.

In Either/Or, Kierkegaard's pseudonymous aesthetic character, A, writes: 'I think I have courage to doubt everything; I think I have the courage to fight everything. But I do not have the courage to know anything, nor to possess, to own anything' (E/O 45). In what follows, I want to explore further A's interesting idea that to know something requires courage by linking it to the previous discussion about epistemic angst and radical scepticism.

In a different Kierkegaardian pseudonymous work, The Concept of Anxiety, Vigilius Haufniensis argues that anxiety is the natural human response to the possibility of freedom. We dread the idea that we are free, because this means having to take responsibility for our choices, which in turn implies that we are to blame if we make the wrong ones. In other words, we are made anxious by the possibility of error, and we try to combat this angst by attempting to abrogate our responsibility for making mistakes. In the context of the previous discussion, this means diminishing our blame for epistemic failure by considering the possibility that we could be in a LE or NBE scenario. For if we were in fact in such a scenario, we would no longer be to blame for our false beliefs and could consequently evade responsibility for them. That is to say, we might, paradoxically, prefer the possibility of being globally wrong but epistemically blameless to being fallible but epistemically accountable. It is easier to blame our epistemic shortcomings on the malicious demon than to accept that we are finite and limited creatures who make mistakes. 
The epistemic moves we are tempted to make here, therefore mirror, in some interesting ways, the aesthete's attempt to avoid responsibility by jettisoning choice (for choice and responsibility are two sides of the same coin). The aesthete believes that there is in fact no real choice available as whatever you choose, you will regret it either way whether you go for something that looks like a good choice or you don't, regret will follow. Hence, on a subjective, phenomenological level, the good choice and the bad choice are subjectively indistinguishable, since they both lead to the same regretful state. One might see a parallel here to what happens, on an epistemic level, if we endorse the Reasons Identity Thesis: If the reasons that the good case provides can never be better than what I have in the bad case, then the difference between the good and the bad case becomes, from my own point of view, almost negligible. Whatever perceptual situation I find myself in, it always, intrinsically, falls short of the facts. Even in the good case, I cannot know that I am not in the bad case, so whether I am in the good or the bad case, it can never make any 'internal' difference to my epistemic situation - my epistemic options are always, in this sense, subjectively bad.

Such a conception may lead to epistemic nihilism - the thought that knowledge is impossible unless I am able, per impossibile, to acquire a 'perspectiveless perspective' - a view from nowhere - which could show me, from no particular point of view, that my subjective vantage point is a view on an 'external world' after all. If what I have argued in this paper is correct, however, such an impossible perspective is unnecessary. There is nothing wrong, intrinsically, with finitude and fallibility. It does not cut us off from having an objective, 'external' world in view. Of course, our perspective is limited and prone to error, but it does not seal us off from the real world altogether (as it would if we were in an NBE scenario). Consequently, we need to find the courage to accept our finitude without allowing ourselves the indulgence of falling into epistemic nihilism. That is to say, we need to accept 
responsibility for our beliefs without seeking solace from the thought that it all doesn't matter because we could be the victims of the machinations of an evil demon or scientist.

If this is right, then we need to let go of the epistemic angst that makes the Cartesian picture (and the Reasons Identity Thesis) hard to dislodge. We can do this, by taking responsibility for our epistemic choices and accepting, as Wittgenstein says, that it is always by favour of nature, not just by one's own efforts, that one knows something ${ }^{21}$. This means that accepting our finitude also implies having the courage to accept the thought that many epistemic parameters are not going to be within our control. But rather than taking this fact, as Kierkegaard's aesthete does, as reason to return the lottery ticket, we need to develop the courage to face epistemic contingency and fallibility without taking false refuge from it in epistemic nihilism or fantastical dreams of self-overcoming (the idea of a view from nowhere).

Knowledge therefore requires courage in (at least) two respects. First, I need to learn to resist the temptation of being seduced by a philosophically dubious picture that appears to suggest that one could be completely cut off from an 'external world' and imprisoned within one's own mind. Second, I need to take responsibility for my epistemic choices in the light of general fallibility ${ }^{22}$. Neither the first nor the second is easy. For even if I am rationally able to see that the Cartesian picture is not adequately motivated, I might nevertheless continue to find it attractive. There is an analogy with cases of addiction or phobia here. Although smokers, for example, are rationally able to see that smoking is damaging to their health, this is not remotely sufficient to stop them from nevertheless finding cigarettes desirable. Conversely, vertigo sufferers are not cured of their affliction by being brought to see that

\footnotetext{
${ }^{21}$ See On Certainty §505: 'It is always by the grace (Gnaden) of Nature that one knows something' (my translation).

${ }^{22}$ Instead of thinking that the possibility of local error (fallibility) implies global error - the thought that I might be completely 'out of touch' with the world. For more on this, see my 2019.
} 
rationally speaking, they have no reason to be afraid of heights ${ }^{23}$. One cannot cure addiction, phobia, or bewitchment by a picture, by rational argument alone.

If this is right, then even in epistemology, work on oneself and one's way of seeing things is required ${ }^{24}$. Radical scepticism is not just an intellectual problem, but also an ethical one - that is to say, it is a problem that engages the whole person (as Cavell was probably the first to notice (see his The Claim of Reason)). Consequently, I not only need to show that an epistemological position is theoretically flawed (although I do need to do that first ${ }^{25}$ ), I also need to expose, then battle against, the angst that propels me towards a particular way of conceiving of the epistemic situation. Kierkegaard's aesthete needs to do something similar he needs to recognize that existential nihilism isn't the only possible response to the contingency, finitude and transience of human existence, and embrace ethical self-choice instead. Both moves require the courage to resist ingrained ways of thinking and behaving.

\section{Conclusion: No Farewell to Epistemic Humility}

Given that making concessions to the sceptic is often associated with the virtue of epistemic humility, does any of the foregoing imply that we are throwing out this virtue and proposing a form of anti-sceptical self-aggrandisement instead? Not at all. Finding the courage not to give in to our epistemic angst also means letting go of our fantastical dreams of absolute certainty, which stand in the way of letting us see that contingency and fallibility do not close

\footnotetext{
${ }^{23}$ I owe this example to Duncan Pritchard. Also see his discussion of vertigo in his 2016.

${ }^{24}$ Compare Wittgenstein: 'Working in philosophy...is really more a working on oneself. On one's own interpretation. On one's way of seeing things. (And what one expects of them)' (Culture and Value 16e).

${ }^{25}$ In other words, I'm not claiming that the Cartesian picture (or radical scepticism) can be undermined by intellectual courage alone. That would be absurd. I first need to start by questioning the theoretical assumptions (which is what I have been doing in two-thirds of this paper), but my argument is that this is often not enough to break the spell that a picture has cast and that intellectual courage is therefore also required.
} 
us off from the possibility of knowledge. For it is these dreams themselves that display a lack of humility, since, from their perspective, nothing non-absolute is ever good enough - just as Kierkegaard's aesthete believes that unless there are absolute values, there can be no values. But this, one might now realize, is an intellectually immature position to adopt: reality (or ethics) is not, if I am right, eternally out of reach because no 'view from nowhere' is possible. Learning to see this is therefore both liberating and humbling at the same time: liberating, because it enables us to see that unless dazzled by the Cartesian picture, we always already have the world in view even though we make mistakes; humbling, because it means letting go of an inflated conception of objectivity and certainty in favour of an apparently more ‘humdrum' one.

And, of course, nothing I have said in this paper implies that we could not be wrong about vast swathes of our beliefs - indeed, it is probably empirically more likely that we have more false beliefs than true ones. It is important to emphasize, however, that these are falsehoods that we could, at least in principle, find out about if only we had more time, paid more attention, were less biased or more intellectually gifted ${ }^{26}$. This ought to motivate us to try harder. If, on the other hand, we genuinely believed that we could be globally wrong about everything, what could it so much as mean to strive to be 'right'? ${ }^{27} 28$

\section{References}

\footnotetext{
26 'Local' sceptical scenarios, in other words, can, in principle, be overcome.

${ }^{27}$ Of course, even in a global vat-world we would presumably go about our business in the normal way and try to have true beliefs. Nevertheless, all this striving would be a sham, and awareness of this possibility demoralising (both for us and our envatted counterparts).

${ }^{28}$ I would like to thank Yuval Avnur, J. Adam Carter and the participants at the Epistemic Vice and Forms of Scepticism workshop (Southampton 2018) for helpful comments on earlier versions of this paper. I would also like to thank the organizer (Duncan Pritchard) and the participants of the Scepticism conference held at the University of California, Irvine in September 2018, for illuminating discussion.
} 
Bostrom, Nick (2003), 'Are We Living in a Computer Simulation?' Philosophical Quarterly $53 / 211,243-255$.

Cavell, Stanley (1999), The Claim of Reason (New York: Oxford University Press).

Descartes, René (1641/1986), Meditations on First Philosophy, trans. John Cottingham (Cambridge: Cambridge University Press).

Dretske, Fred (1969), Seeing and Knowing (London: Routledge and Kegan Paul).

Kierkegaard, Søren (1980), The Concept of Anxiety, edited and translated by Albert B. Anderson and Reidar Thomte (Princeton: Princeton University Press).

Kierkegaard, Søren (1988), Either/Or I and II, edited and translated by Howard and Edna Hong (Princeton: Princeton University Press).

Maddy, Penelope (2017), What do Philosophers do? Scepticism and the Practice of Philosophy (New York: Oxford University Press).

McDowell, John (1998a), 'Criteria, Defeasibility and Knowledge’ in McDowell, J., Meaning, Knowledge and Reality (Cambridge, MA: Harvard University Press), 369-94.

McDowell, John (1998b), 'Knowledge and the Internal' in Meaning, Knowledge and Reality, $395-413$.

McDowell, John (2009), 'The Disjunctive Conception of Experience as Material for a Transcendental Argument' in McDowell, J., The Engaged Intellect (Cambridge MA: Harvard University Press), 225-42.

Nagel, Thomas. (1986), The View from Nowhere (Oxford: Oxford University Press). 
Pritchard, Duncan (2008), 'McDowellian Neo-Mooreanism' in A. Haddock and F. Macpherson (eds), Disjunctivism: Perception, Action, Knowledge (Oxford: Oxford University Press), 283-310.

Pritchard, Duncan (2009), 'Wright contra McDowell on Perceptual Knowledge and Scepticism', Synthese 171: 467-79.

Pritchard, Duncan (2012), Epistemological Disjunctivism (Oxford: Oxford University Press). Pritchard, Duncan (2014), 'Entitlement and the Groundlessness of our Believing' in D. Dodd and E. Zardini (eds.), Scepticism and Perceptual Justification (Oxford: Oxford University Press), 190-212.

Pritchard, Duncan (2016), Epistemic Angst (Princeton: Princeton University Press).

Schönbaumsfeld, Genia (2016), The Illusion of Doubt (Oxford: Oxford University Press). Schönbaumsfeld, Genia (2019), 'How Threatening are Local Sceptical Scenarios?, in Nuno Venturinha (ed.), Special Section on Wittgenstein and Applied Epistemology, WittgensteinStudien 10/1, 261-278.

Sosa, Ernest (1997), 'Reflective Knowledge in the Best Circles', The Journal of Philosophy 94/8, 410-30.

Stroud, Barry (1984), The Significance of Philosophical Scepticism (Oxford: Oxford University Press).

Williams, Bernard (1978), Descartes. The Project of Pure Enquiry (London: Penguin). Wittgenstein, Ludwig (1969), On Certainty, edited by G. E. M. Anscombe and G. H. von Wright (Oxford: Blackwell). 
Wittgenstein, Ludwig (1977), Culture and Value, edited by G. H. von Wright (Oxford: Blackwell). 